\title{
EFFECTIVE EARLY LEARNING: A PRAXEOLOGICAL AND PARTICIPATORY APPROACH TO EVALUATING AND IMPROVING QUALITY IN EARLY CHILDHOOD EDUCATION
}

\author{
Chris Pascal* \\ Tony Bertram**
}

\begin{abstract}
This paper acknowledges the importance of providing high quality early education to young children if positive long term child outcomes and social mobility for the less advantaged are to be achieved. It offers a strategy to improve pedagogical quality in early childhood settings worldwide where quality remains low for many children and sets out an alternative praxeological model of quality assessment and improvement that is democratic, participatory, inclusive and culturally sensitive rather than universalised and metricised. The Effective Early Learning (EEL) quality evaluation and improvement programme embodies this participatory approach and has been successfully implemented across UK, Portugal and the Netherlands, where evidence has shown its impact in enhancing child wellbeing, child involvement and child dispositions to learn through improving the quality of pedagogical processes and the enabling educative context in which these occur.

Keywords: Pedagogic quality. Child outcomes. Participatory evaluation. Praxeological approaches. Child wellbeing.
\end{abstract}

\section{RESUMO \\ PROGRAMA EFFECTIVE EARLY LEARNING (EEL): UMA ABORDAGEM PRAXEOLÓGICA E PARTICIPATIVA PARA AVALIAR E MELHORAR A QUALIDADE NA EDUCAÇÃO INFANTIL}

Este artigo reconhece a importância de proporcionar uma educação inicial de alta qualidade a crianças pequenas visando à promoção de resultados positivos a longo prazo que favoreçam a mobilidade social para os menos favorecidos. Oferece uma estratégia para melhorar a qualidade pedagógica em ambientes da primeira infância no mundo todo, em situações em que a qualidade permanece baixa para muitas crianças, e estabelece um modelo praxeológico alternativo de avaliação e melhoria de qualidade democrático, participativo, inclusivo e culturalmente sensível, ao invés de universalizado e pautado em referências métricas. O programa de avaliação e melhoria

* PhD in Education at University of Worcester/UK. Professor and Director for the Centre for Research in Early Childhood (CREC), St. Thomas Children's Centre, Birmingham/UK. President and Co-Founder of the European Early Childhood Education Research Association (EECERA). E-mail: c.pascal@crec.co.uk

** $\mathrm{PhD}$ in Early Childhood Studies at University of Coventry/UK. Professor and Director for the Centre for Research in Early Childhood (CREC), St. Thomas Children's Centre, Birmingham/UK. President and Co-Founder of the European Early Childhood Education Research Association (EECERA). E-mail: drtonybertram@crec.co.uk 
da qualidade da Aprendizagem Precoce Efetiva (Effective Early Learning - EEL) adota essa abordagem participativa, sendo um sucesso a sua implementação no Reino Unido, em Portugal e na Holanda, com evidências de seu impacto no aprimoramento do bem-estar das crianças, envolvimento infantil e disposições infantis para aprender através da melhoria da qualidade dos processos pedagógicos e da promoção de contexto educativo propício em que estes ocorrem.

Palavras-chave: Qualidade pedagógica. Produções infantis. Avaliação participativa. Abordagens praxeológicas. Bem-estar infantil.

\section{RESUMEN}

\section{PROGRAMA EFFECTIVE EARLY LEARNING (EEL): UN ENFOQUE PRAXEOLÓGICO Y PARTICIPATIVO PARA EVALUAR Y MEJORAR LA CALIDAD EN LA EDUCACIÓN INFANTIL}

Este artículo reconoce la importancia de proporcionar una educación inicial de alta calidad a los niños pequeños para promover resultados positivos a largo plazo que favorezcan la movilidad social para los menos favorecidos. Ofrece una estrategia para mejorar la calidad pedagógica en ambientes de la primera infancia en todo el mundo, en situaciones en que la calidad permanece baja para muchos niños y establece un modelo praxeológico alternativo de evaluación y mejora de calidad democrático, participativo, inclusivo y culturalmente sensible en lugar de universalizado y pautado en referencias métricas. El programa de evaluación y mejora de la calidad del Aprendizaje Temprano Efectiva (Effective Early Learning - EEL) adopta este enfoque participativo, siendo una aplicación con éxito en el Reino Unido, Portugal y los Países Bajos, con la evidencia de su impacto en la mejora del bienestar de los niños, participación infantil y disposiciones infantiles para aprender a través de la mejora de la calidad de los procesos pedagógicos y de la promoción de un contexto educativo propicio en el que estos ocurren.

Palabras clave: Calidad pedagógica. Producciones infantiles. Evaluación participativa. Enfoques praxeológicos. Bienestar infantil.

\section{Introduction ${ }^{1}$}

Across the world changing demographic, social and economic conditions have led to an increase in publicly funded, centre-based, care and education provision for young children At the same time there has been an increasing awareness that ensuring the quality of this provision is critical for children's long term outcomes and that accountability is important when government money is being spent (ECONOMIST INTELLIGENCE UNIT, 2012; PASCAL; BERTRAM; COLE-ALBÄCK, 2017). There are also pressures to universalise early

1 Effetive Early Learning Programme (EEL) foi adaptado, em Potugal, como Projeto Desenvolvendo a Qualidade em Parceria (DQP). O leitor brasileiro pode se orientar por essa denominação na língua portuguesa. Mais detalhes constam em Pascal \& Bertram (1999). childhood provision and develop global metrics to assess the quality and impact of these services (MOSS; DAHLBERG; GRIESHABER, 2016). All of which can lead to the development of provision and assessment instruments that may be perceived as a form of westernised, cultural imperialsim (MOSS; URBAN, 2017). In this paper we offer an alternative, democratic and inclusionary approach to quality evaluation and improvement in early childhood services, which encourages cultural nuance and local interpretation but is based on best evidence of what conditions enable children to maximise their capabilities and lead to enhanced child and practitioner well-being, involvement and learning. This approach is based on a concep- 
tual model of effective early learning with three elements: context, process and outcomes. It also embodies an approach to quality evaluation and improvement which is participatory and inclusive, acknowledging the contribution of all involved in the learning process, including children, parents and practitioners. The Effective Early Learning (EEL) programme embodies this approach and has been implemented successfully in hundreds of early years settings in Europe (particularly UK, Portugal and The Netherlands) and beyond. This paper sets out the conceptual and professional underpinnings of the EEL approach and evidence of its potential impact on the quality of practice.

\section{Underpinning Pedagogic Philosophy}

The EEL Programme has been strongly influenced by the pedagogical philosphy of Paulo Freire (1972) and his passionate plea to employ what he calls a "humanising pedagogy" which has at its heart a permanent relationship of trust and dialogue between teachers and learners, and an engagement in praxis (reflection and action). In this approach, teachers and students are simultaneously acting together to engage in critical thinking and dialogue. Through dialogue and the posing of problems the "teacher of the student" and the "student of the teacher" cease to exist and a new team emerges - the teacher-student with student-teachers. There is joint responsibility for the teaching/learning process in which all participants grow. For Freire, the content or curriculum is not a gift bestowed or imposed but is the "organised, systematised and developed representation to the learners of the things about which they want to know more" (FREIRE, 1972, p. 25). Freire's pedagogy works through people's "thematic universe" to identify "generative themes" which students and teachers identify together and then reflect critically upon. These themes are drawn from the everyday reality and preoccupations of the learner/student. This process leads to conscientization and understanding from which action and transformation can flow. For us, this reinforced the notion that the early childhood curricula and pedagogy should be the result of a negotiated process between adult and child and should build upon a child's interests and abilities as far as possible.
Bruner's emphasis on socio-constructivist learning also helped us in our consideration of pedagogical processes (BRUNER, 1996). Acknowledging Vygotsky (1978), Bruner stated clearly that we learn through interaction with others, and he saw adults and children scaffolding learning for each other. Bruner's thinking encourages the development of 'learning communities' where praxis happens and where learning is not seen as requiring a transmission model but is co-constructed between adult and child. He argued that if we want good learners, who are self reliant, who work collaboratively, then we need another pedagogical model than that of transmission. He believes we need to develop "a sub-community of mutual learners with the teacher orchestrating the proceedings" (BRUN$\mathrm{ER}, 1996$, p. 27). There is also a need to recognise the diversity of cultures. He stated that we know much more about what helps a child to develop into an effective adult learner. Our understanding of the child has grown richer and more complex with new knowledge about the importance of self initiated activity, the impact of a responsive social environment and the construction of selfhood. But he believed, and we agree, we have a long way to go to construct an approach to early education which fits the complicated cultural and social conditions in which we live today. "We need to rethink our current pedagogical practice if we are to support the notion of active, questioning children seeking greater mastery over their worlds" (BRUNER, 1996, p. 29). These reflections helped us to think through and focus our exploration of what kind of learning was being promoted by the pedagogies and curriculum being offered in the settings in which we were working. It also sharpened our determination to look at early learning with a more transformative eye and to aspire to the creation of new pedagogic practices.

\section{Our Praxeological Approach}

The discipline and practice of participatory, practice-led research and development (EISENBERG; BAGLIA; PYNES, 2006; McNIFF, 2010; REASON; BRADBURY, 2008) has grown rapidly in recent years and it is now widely accepted as making an important and serious contribution 
to the knowledge base of early childhood. Over many years, our work in Centre for Research in Early Childhood in Birmingham, UK (CREC), has embraced, exemplified and contributed to this development of practitioner researchers, action researchers and practice-based researchers (KOSHY; PASCAL, 2011; PASCAL, 1993, 2003; PASCAL; BERTRAM, 2012). We have also made visible our continuing struggle to operate authentically within a participatory worldview in the belief that early childhood research and development should and could be more democratic, participatory, empowering and should also be deeply ethical and political in its orientation (PASCAL; BERTRAM, 2009). We accept that praxis in itself is not enough, and that to authentically realise a participatory paradigm in our work requires us to develop a worldview in which reflection (phronesis) and action (praxis) done in conjunction with others, needs to be immersed within a more astute awareness about power (politics) and a sharpened focus on values (ethics) in all of our thinking and actions. We see this mix of phronesis, praxis, ethics and power at the heart of what we increasingly recognise as a "praxeological" worldview in modern early childhood research (PASCAL; BERTRAM, 2012). In this development we should acknowledge our important collaboration with our Portuguese colleagues, João and Júlia Formosinho and their team at the research centre of the Childhood Association in Braga (FORMOSINHO; OLIVEIRAFORMOSINHO, 2012).

For us, "praxeology" describes the theory and study of "praxis" - defined by Freire (1972) as "reflection on, and in, [human] action" -, and embeds this in a situated context in which power and ethics are fundamentally realised and explored in an attempt to engage in participatory practice. We have always aimed to realise praxis in our research, but we now prefer this Greek term, "praxeology", as a better descriptor of our developing research paradigm in which we are foregrounding much more issues of power and ethics in the way we work in a participatory relationship with our collaborators. The focus on praxis is thus not simply about everyday practicalities, professional development, competencies, skills or outcomes, but about deeper concepts, reflexivity, processes, actions and interactions and which are deeply cognoscente of environments of power and values.

Praxeological research and development is often about the individual and specific case but it always involves and is contextualised by the group and the community. Praxeological research is always situated within a specific context and so embraces localism but it is also democratic and participatory in the wider sense of society. Lave and Wenger's (1991) ideas on "communities of practice", for example, can be seen to underpin and support this social and collaborative approach. Praxeology foregrounds participation, voice and democracy, in which individuals are acknowledged but as members of a wider community. Because there is nothing as culturally and individually located; nothing as central to our concept of identity and belonging as our own child rearing practices, early childhood research must recognise and be sensitive to these core significances and cultural diversities inherent in its field of study. Praxeology is careful of generalisations and universals and of reducing these complexities to numerical representations which deny people's plurality. In this approach, knowledge is viewed as soundest and trustworthy when it is co-constructed and validated by those who are in the field of inquiry. It purports that knowledge can be localised and yet still be authentic, genuine, be meaningful and have transferability.

Thus, we are very aware that learning takes place in a highly complex and context dependent situation where unpredictability and individual idiosyncrasy are the norm. In the EEL Programme we have attempted to implement a methodological approach that embraces this reality and were inevitably drawn to hermeneutic/interpretative paradigms which acknowledges the subjectivity, complexity and irrationality of the real world. We were happy to consider a "choice of paradigms" and use multi-methods in the construction of a quality evaluation and improvement process which was inclusive of children, families and settings because we believe the world and knowledge is multi-faceted, and context dependent, and therefore demands a multi-faceted approach.

We are committed to an approach to quality evaluation and improvement which is collaborative, participatory, empowering and developmen- 
tal for all involved. When developing the EEL Programme we therefore adopted a "democratic" approach to the work because we wanted to ensure that it was a process that was "done with" participants rather than "done to" them. In this way the evaluation process becomes a learning experience for all involved and aims to generate knowledge and understandings that will feed directly into the further development of practice. It was also anticipated that the shared ownership of the evaluative activity would lead to a greater commitment by those involved to any suggested developments and transformations. In this way quality evaluation and improvement go hand in hand.

We also adhered to a set of ethical principles which ensured the evaluation activity:

- $\quad$ is developmental and service led;

- follows an agreed framework, and a set of research guidelines, which are negotiated with all those involved;

- uses and extends the skills of practitioners and local community members;

- is done "with" participants not done "to" them;

- is ethically conducted in an open and honest manner with the consent of all participants;

- is collaborative and inclusive;

- $\quad$ is empowering and developmental for all participants;

- has utility for all participants;

- respects the values and wishes of all participants;

- protects the participants from risk of any harm or threat to their personal or professional activity;

- $\quad$ respects the confidentiality and anonymity of participants at all times, unless otherwise agreed by all parties;

- $\quad$ respects the professional and personal wellbeing of participants;

- feeds back any resulting evidence to participants.

The EEL Programme is also based on our critical reflections about what research has shown to be an effective early learner and what we know about developing quality in early learning settings. Through the programme, we are attempting to encourage those who work with young children to apply this new knowledge to their practice and use it to transform their practice.

\section{Defining Quality in Early Childhood Settings}

The EEL programme acknowledges that quality ultimately is a value laden, subjective concept, which has a dynamic aspect and that quality varies with perspective, with time and with place (PASCAL; BERTRAM, 2012). However, whilst we acknowledge that definitions of quality are context dependent and that quality improvement requires local cultural realities to be negotiated, we also accept that care must be taken not to adopt too fully deconstructive, relatavist solutions. Our aim in the Programme has been to offer practitioners and providers a rigorous and systematic way of evaluating and improving quality through a participatory process which allows local interpretation and contextualisation.

While it is important to set out national minimum standards or expectations to which all providers should comply, there is a need for improvement processes that take settings beyond this and promote a culture of continuous quality improvement. The intention of the EEL Programme therefore is to provide all settings with the means to:

- capture, accurately and rigorously, the essence of educational quality as it is reflected in practice;

- explore how the individuals in each setting, including parents/carers and children, perceive and experience the quality of education provided;

- plan, after reflection, for specific and achievable improvements in that perceived educational quality.

The intention of the EEL Programme is to take every setting forward, improving on their "previous best" by systematically and rigorously undertaking a prolonged period of self-evaluation which, through externally moderated action planning, leads to improvement. Educational quality is not therefore a ceiling which is reached, or a line which is crossed, but is a continuous and on-going journey of improvement. This is the essence of the EEL approach to quality. 
The conceptual framework which defines our approach to quality in early learning has been informed by a number of writers on effectiveness in learning (KRYIACOU, 1994; LAEVERS,
1994; MUNTON; MOONEY; ROWLAND, 1995; ROSSBACH; CLIFFORD; HARMS, 1991). The EEL framework for defining and evaluation quality is set out in Figure 1.

Figure 1 - A Conceptual Framework for Developing Quality in Early Childhood Education and Care Settings

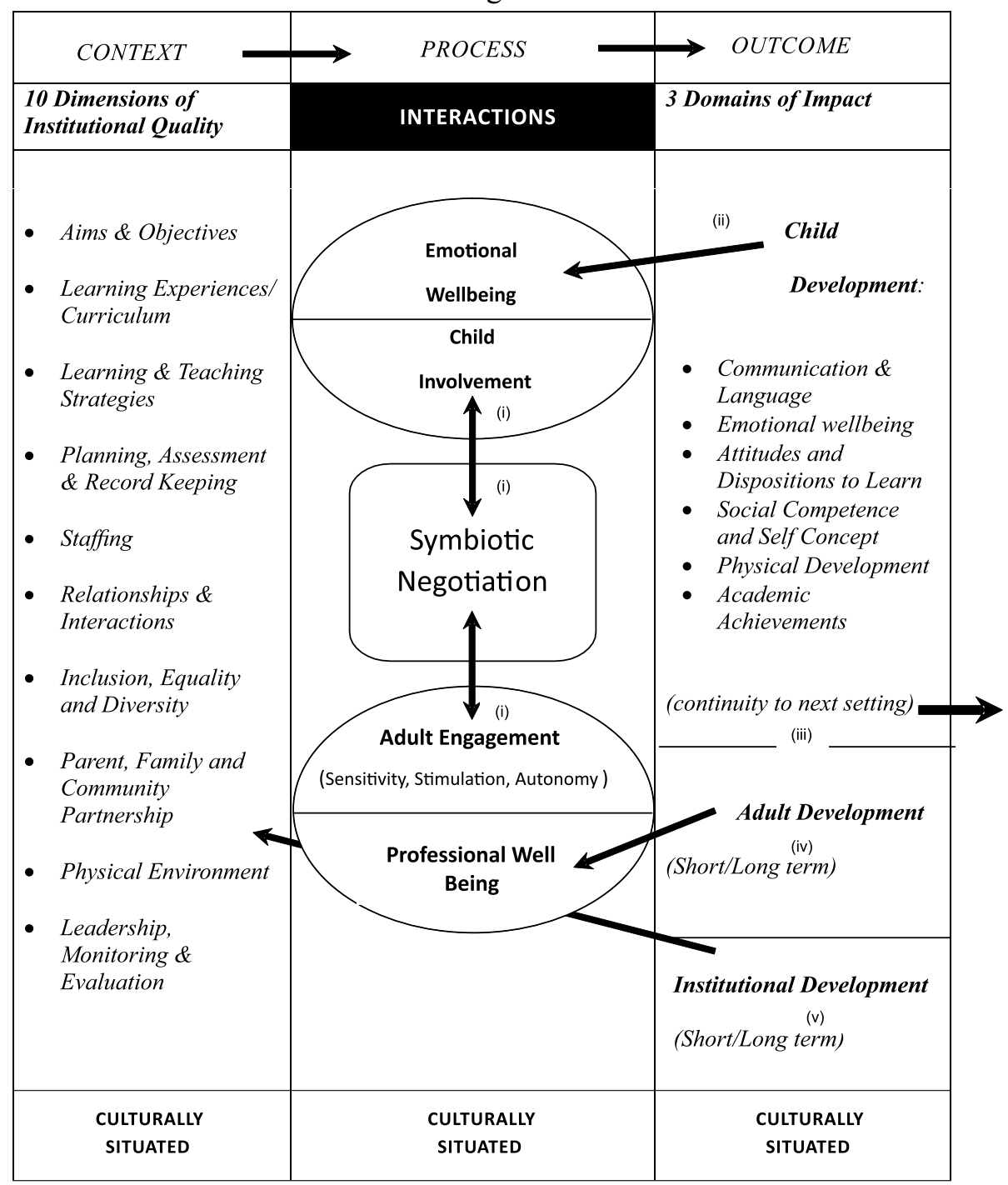

Source: Pascal \& Bertram (1996, p. 18).

In this framework, quality provision for early learning is viewed as having a temporal sequence of three overaching dimensions categorised as Context, Process and Outcomes. Essentially, Context is viewed as the set of variables which describe the circumstances and the environment that enable learning in the early childhood setting. The Process is concerned with dynamic and interactive variables within the described context through which learning occurs and the Outcomes are the results and impact of that dynamic and interactive process. It should also be noted that in reality this temporal sequence does not occur as a linear, progressive process but rather each of the three dimensions interacts with and influences the others in acontinous, dynamic flow of actions, 
interactions and reactions. The complex dynamic of teaching and learning processes should not be lost when considering each element in turn.

\section{Context: The Enabling Environment}

The EEL Programme has developed a set of 10 context indicators which reflect best evidence about what characterises an enabling environment for early learning, and these are outlined below.

\section{Aims and Objectives}

This dimension refers to the written and spoken statements of policy within a setting in which the aims and objectives of the provision for care, learning and play are made explicit. It reveals the setting's underlying values, beliefs and attitudes to young children's care and learning. It focuses on issues such as how the policy statements are formed, who is involved in their formation and how they are communicated to all parties. The extent to which these aims are initiated, shared, communicated and understood by all the involved parties needs to be considered. It reveals the settings underlying values, beliefs and attitudes to young children's care, learning and play.

2 Care, Learning \& Development Experiences

This dimension is concerned with the range and balance, learning and development experiences provided, and the opportunities presented for young children. The experiences are interpreted very broadly to embrace children's all round learning and development including:

- personal, social and emotional development;

- communication, language and literacy;

- problem solving, reasoning and numeracy;

- knowledge and understanding of the world;

- physical development;

- creativity.

\section{Facilitating Care, Learning \& Development Experiences}

This dimension focuses on how the experiences are planned and organised to encourage care, learning and development especially through play and interaction. Key issues include the interactions within the setting, the extent of children's independence and autonomy, and opportunities for active, self-directed and self-managed learning.
This dimension also gathers evidence about how children's behaviour is managed and the participation of parents/carers and children in this process.

\section{Planning, Assessment and Record Keeping}

This dimension analyses how learning is planned and raises issues such as who is involved in the planning process and how far the planning builds upon previous assessment of children's activity. The assessment of children is considered, and the efficacy of the methods of documenting children's activities and experiences are noted. Accessibility, sharing and usage of documentation are also considered within this dimension.

\section{Staffing}

In this dimension evidence is gathered on issues of staff/volunteers' experience, qualification, deployment, ratios, vetting, management supervision and appraisal. Opportunities for professional development and training are documented, with emphasis placed on the professional well-being of the staff/ volunteers and the development of a cohesive, competent staff/volunteer team, which is well motivated and open to innovation and improvement.

\section{Relationships and Interactions}

This dimension gathers evidence on the relationships of children and adults within the setting. Evidence is gathered by observing systematically the educative interactions between children and adults within the setting by assessing levels of "Child/Adult Engagement". In addition, time lapsed observations are also taken of a child's experiences through the day and the nature of their interactions with peers and adults, individually and in groups. The level of "engagement" of the children provides an accessible and explicit measure of the quality of the learning experience. In addition, consideration is given to the expectations of behaviour by parents/carers, staff/ volunteers and children and how these are linked to agreed and shared strategies.

\section{Inclusion, Equality and Diversity}

This dimension provides evidence of the way in which the setting, the participants and the learning experiences, reflect, acknowledge and celebrate diversity, and the extent to which the ethos is respectful and inclusive. An awareness of diversity includes 
respecting differences of race, gender, religion, ethnicity, disability and special educational needs. The equipment and the activities should be considered with regard to equality. In particular, evidence will be gathered on provision for children with special needs.

\section{Parent/Carer Partnership, Home and Com- munity Liaison}

This dimension focuses on collecting evidence on the nature of the partnership with parents/carers and families, and the ways in which they, and other members of the local community, are involved in the learning process. Links between the setting and other early childhood settings, which the child may have attended previously, may be attending consecutively or may attend subsequently, are important. Evidence is also collected on how the setting monitors and implements child protection procedures and the required protocols.

\section{Physical Environment}

In this dimension the context in which the learning occurs is analysed. The use of space and resources, both inside and out, and the availability, condition and appropriateness of the learning resources, equipment and materials are documented. Issues of safety and health and the management of food and drink are also addressed in this section.

\section{Leadership, Management, Monitoring and Evaluation}

This dimension provides evidence on how the setting manages, monitors and evaluates its activities. It considers leadership and management systems and structures, procedures for quality evaluation and improvement, and how far records, policies and procedures support the effectiveness, efficiency and safety of the provision.

\section{Process: Adult Engagement/Child Involvement}

The EEL Quality framework has at its heart an interactive dynamic between children and adults which takes place within the context of the setting. The quality of the interpersonal pedagogical exchange between adults and children is recognised in this framework as critical to learning and we have drawn on the two key concepts of Child Involvement, as developed by Laevers (1994), and Adult
Engagement as developed by Bertram (1995), to capture quality in this important dimension.

Child Involvement is a quality of human activity and is characterised by a state of flow (CSIKSZENTMIHAYLI; NAKAMURA, 1979), which is taken as evidence that a child is experiencing deep level learning. What Laevers calls "involvement" (LAEVERS, 1994) can be observed as physical signals that the child displays and which are rated on a 5 point observational scale. Involvement is a measure that can be applied to learning at all ages and there is evidence of the significance of this capacity as an indicator of learning. An involved child narrows their attention and is rarely distracted, they persist and are focused, intrinsically motivated and absorbed by their activity. For the child, time passes quickly, they are extremely alert and respond quickly. An immense amount of energy is often released and children appear vitalised. They will talk to themselves and make facial expressions which convey intensity of attention. It is suggested by Laevers (1994) and Pascal and Bertram (1996) that these signals are picked up by effective, responsive teachers. Involvement can be distinguished from other intensely experienced drives whcih derive from different needs, such as emotional needs. Involvement arises fromt he innate exploratory drive within the child, the need to find out about the world and the need to link up with others who will help the child to realise their desires. It is centred on social cognition and the Vygotskian notion that learning takes place in a social context through interaction. The Vygotskian concept of "zone of proximal development" (VYGOTSKY, 1978) in which the child is at the limit oif their intellectual capability supported and extended by a "scaffolding" adult (BRUNER, 1966) supports this notion.

The concept of Adult Engagement focuses on the adult's role in the setting (BERTRAM, 1995). It describes the quality of the adult's interaction with the children and focuses on three elements of that interaction: Sensitivity, Stimulation and Autonomy. The concept of Adult Engagement, which describes the adult's "teaching" role is balanced in the quality framework by the concept of Child Involvement, which describes the child's "learning" role at that point in time. The two partners in the pedagogic process appear to be in a symbiotic relationship, 
that is, as children become more or less involved the adult appears to be more or less engaging, and this relationship is characterised by ongoing negotiation.

In summary, Process in the EEL quality framework is seen as a symbiotic and negotiated pedagogical relationship between adult and child. It is symbiotic in the sense that not only does the adult's style of pedagogical engagement effect the children's level of involvement, but the children's involvement effects the adult's style of engagement. Involvement and Engagement in pedagogical interactions do not operate in a strelised envieronment. Both are dependent on the ecology of social psychology. The "emotional well-being" of the child effects the child's capacity to become involved in the learning opportunities offered. The adult is similarly influenced by an affective dimension, which we term "professional well-being".

\section{Outcomes: An Effective Learner}

In the EEL Programme we set out to evaluate how far the setting enables the development of an effective learner, as viewed in Figure 2.

Figure 2 - Framework for an Effective Learner

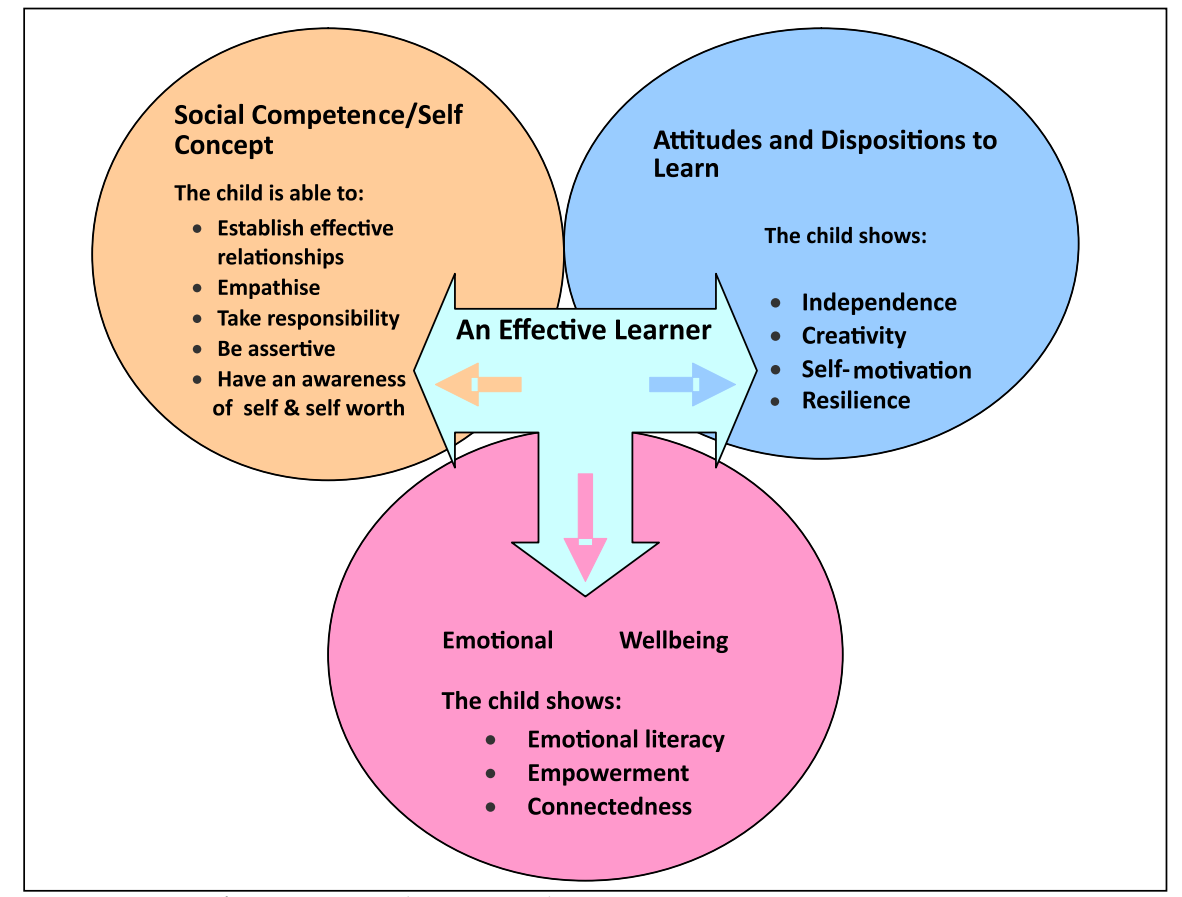

Source: Pascal \& Bertram (2008, p. 7)

This framework highlights three domains of effective early learning which have been directly shaped through our critical reflections and case studies of children. As stated earlier, these domains are not discreet but are intimately inter-related, each influencing and being influened by, the others.

\section{Emotional Well Being}

The first domain focuses on children's emotional well-being and their ability to feel comfortable with themselves and has been largely informed by Laevers (1994) work. For Laevers, emotional well-being is demonstrated in the child displaying an open, receptive attitude to the environment. This open attitude enables the child to be assertive and to show and manage their emotions. They will also reflect peace, vitality and zeal for life and will enjoy participating without too much anxiety. Such qualities are seen to be critical in sustaining learning in the long term and to sustain the child through difficulties and learning challenges. This domain has four key elements.

Emotional Literacy: A key element of emotional well-being is the ability of the child to be emotional literate. This reflects the child's fluency in both feeling and expressing their emotions and 
being able to pass through a range of feelings towards a sense of equilibrium. The emotionally literate child is aware of their emotions and is able to articulate and express them. The child shows self-control and is able to manage a range of emotions. They are able to be self-motivated and persist in the face of adversity. The child shows the ability to empathise with others and has a growing understanding of the effect of their actions on others. The fundamental influence of emotions on learning and on the child's ability to free their exploratory drive is often under estimated.

Empowerment: The empowered child has an inner strength and robust self-will which encourages self-direction and self-management of new learning. The child has a strong sense of self-worth, identity and confidence. The child feels able to trust and is able to determine her own actions, appreciate the consequences of these actions and to make choices. An empowered child can cope with changes in their life and has a sense of self value, knowing that their emotional needs will be met, being unafraid to ask for support when required.

Connectedness: A further precondition for emotional well-being is that of connectedness or togetherness. To learn effectively the child requires an ability to relate to others, to interlink events and situations in their life and to feel a part of the whole. They also need to have a sense of attachment and belonging to the people with whom they come into close and regular contact, both adults and children. The community in which the child operates provides the context in which a child feels their sense of value and within which they are able to participate. The connected child will have a working knowledge of the pattern of their day to day life, how things function and will feel able to contribute to and shape this.

Positive Self Esteem: A major contributing factor to emotional well-being is positive self-esteem. This indicates the child's sense of self-worth and personal identity and the way in which this is perceived by the community of adults and children within which they operate. Self-esteem is shaped first by the experiences of the child in relation to others but reflects the child's own perception of self and the value that they believe this self is given in relation to others. The child with positive selfesteem feels capable, significant and worthy but not necessarily perfect, and does not feel the need to strive for perfection. Positive self-esteem allows the child to have a realistic appraisal of self and to deal with her feelings, both positive and negative, in relation to risk, success and failure. These are key skills for the effective learner.

\section{Social Competence and Self Concept}

Social competence is the second core element of the framework and may be defined as the ability of the child to reach out to others and to make connections and relationships that help them to survive and thrive. These competencies provide the child with the mechanisms to interact and interrelate with their community, a precondition for successful social living. The need for interdependency, a moral conscience and inner discipline are central to participation within a social network. A further precondition for developing effective relationships is that of self-concept, which provides the child with a strong sense of their own identity or worth. Self-esteem provides the child with the inner confidence to reach out and explore the unknown and forms a base from which they will form respectful relationships with others. These competencies are critical for learning which is essentially a social process. This domain has five key elements:

Establishing Effective Relationships: A key social competence is the ability of the child to establish effective relationships with other children and adults. These relationships are crucial to the child's survival and healthy development. It requires the child to have the ability to initiate interactions, to cooperate with others, to accept others ideas and suggestions and to share experiences. The ability to make strong and close friendships with more than one person signals a child's connectedness and interdependency and will support their place within a learning community.

Empathy: The ability to empathise is a social competence by which the child can understand the world from another's perspective. This is required for developing social relationships and cooperating within collaborative group learning situations. The empathetic child behaves considerately towards others and shows respect for other people, their 
feelings and intentions. A sensitivity to the social context in which they are operating and the effect this context has on themselves and others is reflected in the child's actions and responses.

Taking Responsibility: The ability of the child to take responsibility for their own thoughts, intentions and actions is a core social competence for successful learning. This competence is an essential determinant of effective social functioning. This indicates the child's developing sense of right and wrong and awareness of appropriate behavioural expectations; the child will have a moral self and an inner discipline. The child's actions show a strong internal locus of control along with an ability to treat others with respect, care and concern.

Assertiveness: The ability of the child to be assertive is a social competence that provides the child with the capacity to influence and shape their learning and their lives. This gives the child the capacity to make and carry through decisions and to have a sense of themselves as an active and valued member of a community of learners. The assertive child will communicate and voice their opinions and ideas, offer suggestions and negotiate. They will question and be inquisitive but listen to others opinions and suggestions. This will be reflected in their interactions which will be without aggression or undue deference or evasiveness.

Awareness of Self: A key precondition for effective social interaction is the child's developing sense of self and self-worth in relation to their personality, their family, their home and their culture. This competence is reflected in the child's understanding of their own personal identity and sense of belonging. The child with self-worth will have a positive self-image and demonstrate selfesteem. They will show a sense of control over their decisions and rights and have pride in their achievements. They will also have a developing capacity to reflect upon their sense of self in relation to the world.

\section{Attitudes and Dispositions to Learn}

Attitudes and dispositions are the third key element of the framework and may be defined as behavioural characteristics and attitudes, exhibited frequently in young children and in the absence of external coercion, threat or reward, which indicate internalised habits of mind under conscious and voluntary control. Dispositions can be positive or negative. Educative dispositions are seen as positive when these behavioural characteristics are intentionally oriented to achieving broader goals than specific curriculum knowledge. Positive educative dispositions, which have long term effects on lifelong learning, include independence, creativity, self-motivation and resilience. Dispositions are environmentally sensitive. They are acquired from and affected by interactive experiences with the environment, significant adults and peers. Unlike genetic predispositions, dispositions are not fixed at birth but are dynamic. Positive dispositions are learnt but they are rarely acquired didactically. These dispositions are central not only to educational achievement but to personal fulfilment. This domain has four key elements.

Independence: A disposition towards independence is revealed by a child's ability to be self sufficient, to self organise and self manage. The independent child is as equally comfortable in exercising choice as she is in taking responsibility for her decisions and actions and their consequences. Independently disposed children enjoy opportunities for autonomy and choice making. They are strong enough to ask for support when required from adults or their peers, to ask questions and to negotiate opportunities for choice. They can be assertive when needed but without resort to threat or dominance. Independently oriented children are capable of making selections and of locating and using resources appropriately. They develop competencies in organising their environment, including the human environment, which allow them to have agency and affect change.

Creativity: A disposition towards creativity is characterised by those children who show curiosity and interest in their world, reveling especially in serendipity and originality. Such children enjoy exploring their environment, looking for patterns of meaning and comparing similarity and difference. The creative child is imaginative, spontaneous and innovative. They instigate and expand play ideas. They are secure enough in their immediate world to venture forth to explore new boundaries especially within the exciting zone of proximate development. They enjoy developing and extending their knowl- 
edge and thinking. They are rarely timid or fearful but have a confidence, which allows them to embrace the undiscovered with enthusiasm, boldness and wonder. They can think laterally, innovatively and reflectively. Their confidence, originality and creativity is often expressed through humour. Satisfaction and reward from their exploration, allows them to feel comfortable with the original and the different. Internally strongly located with an established self-identity based on secure notions of belonging, they can take risks and have satisfying adventures and face their world openly.

Self-Motivation: A disposition towards selfmotivation allows children, independently, to become deeply involved and engrossed in activities and challenges. Characteristically, they have plenty of self-initiated purposes, plans and objectives. They often will declare aims and goals and the intention to achieve them. Highly self-motivated children appreciate effort as a strategy and they show determination, persistence and precision. These well-motivated children are self-driven towards achieving their goals and the energy of their exploratory drive will be apparent. They also understand that mastery is a continual process of trial, error and adjustment. They see "failure" as a temporary state, simply an intermediate part of the learning process and certainly not an indication of any fundamental and continuing personal inadequacy. They develop positive mindsets, such as: "let's try", "have a go" and "can do". They are smilingly keen to display newly acquired knowledge and skills, "watch me", "look at this" and "did you know?". These children will self-manage, develop self-efficacy, and make choices to achieve their goals.

Resilience: A resilient child has the disposition to bounce back after setback, hindrance or frustration and retain temperament, personality and spirit. Such children develop a varied range of strategies for coping with change, recovering quickly and rebounding from disappointments. They are usually confident with an internal locus of control. Their resilience makes them happy with new challenges and often keen to try to tackle problems themselves. Although they appreciate the need for boundaries and structures, when routines are altered they are flexible and remain secure. They will sometimes develop self-survival mechanisms which allow them to vary their dependence on significant others without losing the bond. When reprimanded, they can separate errant behaviour from personal identity. They appreciate their right and that of others to have a different opinion. They understand the rewards to be gained from the processes of engagement, negotiation, assertion and persuasion. They understand that usually authority is logical but they are strong enough to know that sometimes adults get things wrong and, temporarily, that is something with which you may have to live. They understand that, in endeavour, setbacks are inevitable but they also know that there are limits to the extent one should strive without reward. They appreciate that sometimes it is reasonable to persist and sometimes it is reasonable to quit, sometimes you need to stand up and shout out and sometimes you need to be quiet and give way. They have strategies for conflict resolution.

Finally, this framework has at its heart the notion of an effective early learner. This learner is characterised by a capacity to sustain their ability to explore the world in an open, critical, creative and joyful way in order to extend their knowledge and understanding. Central to this ability is a sense of "agency". Agency is fundamentally about empowerment. A learner with agency is able to function effectively within a social community but is capable of acting upon and within that community with sensitivity and a sense of belonging. This sense of agency and empowerment frees the child's exploratory drive and allows their natural curiosity to emerge. They will also have a sense of participation and influence upon their world, which motivates them to engage in a socially constructive, inclusive and equitable way. They will have the social and emotional skills and competencies to engage with others, access opportunities and express their needs as they take their learning forward.

In short, an Effective Learner has competencies which are about their "internalised self" and competencies which are about their "extended self" or self in relation to others. A young child with these competencies:

\section{Internalised Self Competencies:}

- Is empowered and operates as a subject not an object;

- Has a sense of instrumentality and causality; 
- Is able to assert and articulate her sense of self and self direction in relation to others;

- Is able to act on her own behalf and her actions come from her sense of self and self will;

- Takes her own decisions in relation to her life;

- Is able to, and enjoys, taking responsibility for herself, her decisions and her actions.

\section{Extended Self Competencies:}

- Has a sense of belonging and interconnectedness;

- Is able to negotiate authority;

- Has empathy and operates in reciprocity with others;

- Has autonomy within the boundaries of accountability.
Using this framework we have developed clear descriptors for each of the three domains of learning, and an instrument to document, assess and celebrate the child's developmental achievement, rated on a five point scale for each domain. After applying these assessment scales, practitioners and parents work together to identify and develop effective intervention strategies to support and nurture further these elements of early learning.

\section{The Participatory Evaluative Method}

In the EEL Programme, early childhood settings become sites of praxeological, action research where practitioners work with parents and children collaboratively and systematically to collect evidence to evaluate each element of the quality framework. The action research process is set out in Figure 3.

Figure 3 - The EEL Quality Evaluation and Improvement Process

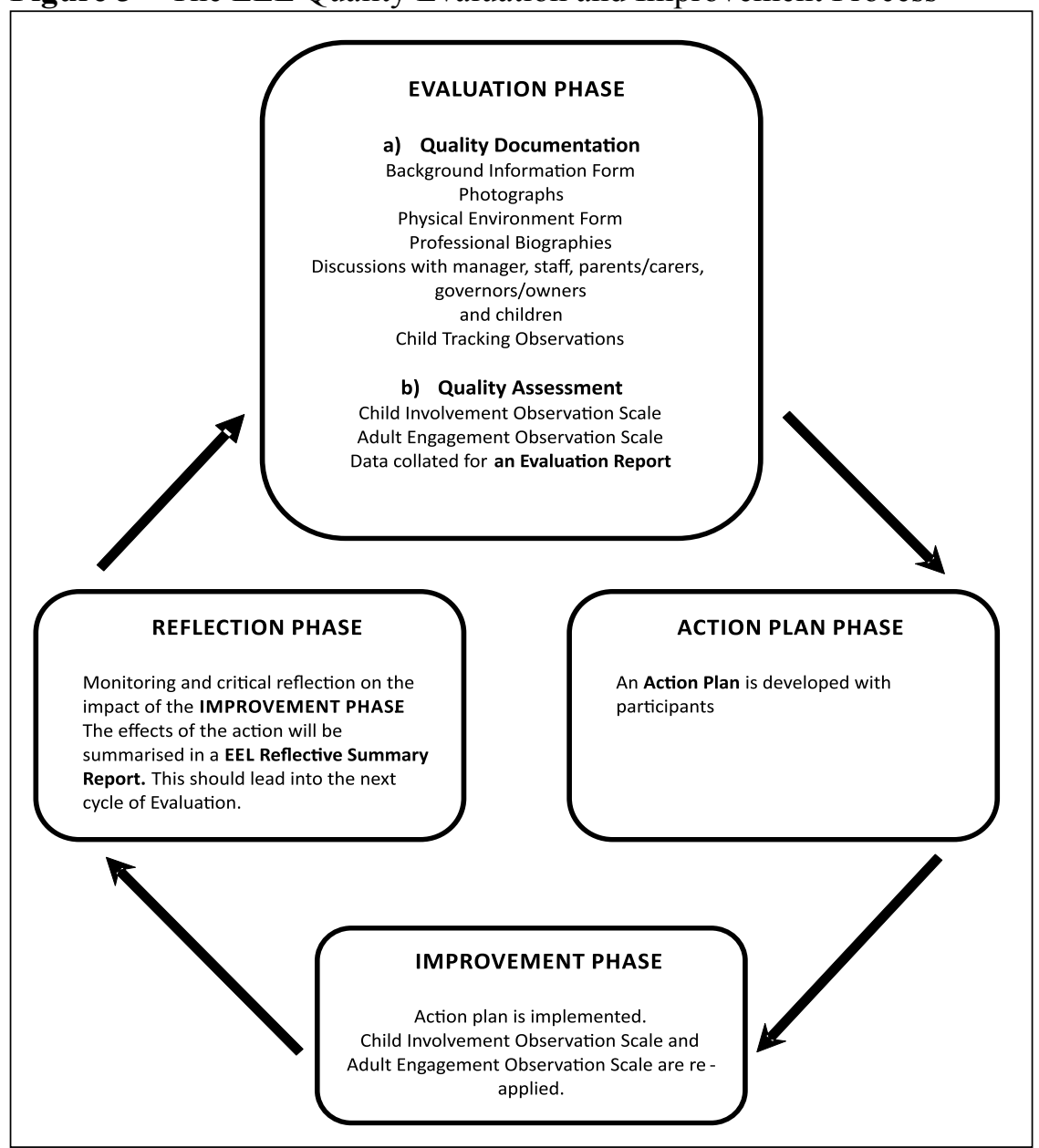

Source: Pascal \& Bertram (1996, p. 21). 
The evaluation process is supported by a set of observational and narrative instruments which collect the perceptions and experiences of staff, children and parents to create an indepth picture of the quality of teaching and learning in a setting. This evidence is then critically reflected upon by all particpants and used to develop an action plan for improvement. An important feature of the quality framework is that it does not seek to tell participants what their improvement points should be, but provides clarity and information about what qualities the settings is currently achieving. From this, the participants make judgments about what they can celebrate and what they would wish to change and improve. In this way, the evaluation process sets out to empower those within it, and give them a sense of their own agency and responsibility to enact change or not.

\section{Impact of Participatory Quality Improve- ment Process}

The EEL process of quality evaluation and improvement has been implemented in many hundreds of settings over the last 25 years. We have documented evidence that the process has the potential to significantly improve the quality of teaching and learning envirornment and pedagogical processes. More importantly, there is evidence that these improvements have led to enhanced outcomes for children, particularly in the securing enhanced well being, involvements and learning dispositions (PASCAL; BERTRAM; MOULD, 1998). Research on the EEL process in Portugal also demonstrates the perceived effects of the process of staff development on professional learning at the level of observation skills, reflection-on-action and critical insertion. Also, the participants recognised that experimentation in practice contexts and shared reflection were the most meaningful and facilitative strategies in their learning (ARAÚJO, 2015).

\section{Final Reflections}

The underpinning rationale for this praxeological and particpatory approach to quality evaluation and improvement rests in ideas of collegiality, democracy, distributed power and transformative practice. If it is accepted that quality is a relative, dynamic and value-based term, then it is important that as far as possible, everyone's views should be included. This inclusionary model of evaluation values dialogue, subjectivity, rights, exchange, transparency, diversity, empowerment and democratic particpation. It recognises that quality in early childhood settings can be achieved in a variety of ways which are respectful of cultural diversity and nuanced realisation. In this way, it empowers those involved in the provision to make their own informed and supported judgements about the quality of practice offered and avoids prescription. It is culturally sensitive and respectful, acknowledging individual context, process and child outcomes as co-dependent aspects of quality early learning in real world settings. This apprach constrasts sharply with a disturbing landscape of competing and often conflicting counter narratives about quality teaching and learning, all of which appear to make the claim to be evidence based. This duality of perspectives may explain some of the tensions and stresses experienced by those at the front line of practice, the teachers and the children, who may be seen as "squeezed" in this culture of competing narratives and often, demands. Examples of these competing narratives include:

1. Performance readiness versus relational readiness;

2. Play based learning versus formal instruction;

3. Child led versus teacher led pedagogy;

4. Improving practice versus inept practice;

5. Cognitive versus non-cognitive outcomes.

This dissonance is reflected in the statement that: "all sides recognise the importance of a child's earliest years of education, but differ profoundly in their understanding of how this should be manifest in policy and enacted in practice." (NEAUM, 2016, p. 249).

In a paper we presented in 1997 (PASCAL, 1997) we argued that it was time we moved on from a purely cognitive approach in early childhood education and embraced a more humanising approach, which acknowledged the socio-emotional elements of early learning and set early childhood within its wider social context. If anything, this agenda has become even more urgent. We believe there is even more evidence of the increasing dehumanisation of 
the modern world, in which many people's lives are blighted by injustice, alienation and violence, and in which inequality and social exclusion continue to be major challenges. In a humanistic approach, all children and their families are seen as valued and active members of a society, and it is their interactions with professionals, their neighbours and their local community that will determine the future shape of their world. We believe this democratic and participatory approach is not only possible but lies at the heart of good early childhood practice and policy. We now know that focusing on the development of human potential in the broader sense, and in particular, on the development of socially and emotionally competent children who have a strong sense of belonging and self identity, will provide us with the stability and security that all developed and civilised societies require to progress. We also know that governments that promote this human or social investment approach are more successful and efficient in building cohesive, stable, inclusive societies. When considering the quality of our early childhood services we believe that we should start by foregrounding those child outcomes which will be required to live well and humanely in the $21 \mathrm{st}$ century, such as child wellbeing, involvement and creativity, and also promote the active participation of children in creating their worlds.

\section{REFERENCES}

ARAÚJO, S. B. Professional development within the effective early learning programme: a contribution to a participatory and context-sensitive approach to ECEC evaluation. Early Years, v. 35, n. 3, p. 249-259, 2015.

BERTRAM, T. Adult engagement styles and their use in staff development. In: EUROPEAN EARLY CHILDHOOD EDUCATION ASSOCIATION CONFERENCE, 5., 1995, Paris. Annals... Paris: European Early Childhood Education Research Association, 1995.

BRUNER, J. Towards a theory of instruction. Cambridge: Harvard University Press, 1966.

The culture of education. Cambridge: Harvard University Press, 1996.

CSIKSZENTMIHAYLI, M.; NAKAMURA, J. The concept of flow in Play and Learning. New York: Gardner, 1979.

ECONOMIST INTELLIGENCE UNIT (EIU). Starting well: benchmarking early education across the world. Hong Kong: Economist Intelligence Unit, 2012.

EISENBERG, E. M.; BAGLIA, J.; PYNES, J. E. Transforming emergency medicine through narrative: qualitative action research at a community hospital. Health Communication, v. 19, p. 197-208, 2006.

FORMOSINHO, J.; OLIVEIRA-FORMOSINHO, J. Towards a social science of the social: the contribution of praxeological research. European Early Childhood Education Research Journal, v. 20, n. 4, p. 591-606, 2012.

FREIRE, P. Pedagogy of the oppressed. Harmondsworth: Penguin, 1972.

KOSHY, V.; PASCAL, C. Nurturing the young shoots of talent: using action research for exploration and theory building. European Early Childhood Education Research Journal, v. 19, n. 4, p. 433-450, 2011.

KRYIACOU, C. Effective teaching in schools. Hemel Hempstead: Simon and Schuster Education, 1994.

LAEVERS, F. The leuven involvement scale for young children LIS-YC. Leuven, Belgium: Centre for Experiential Education, 1994. (Experiential Education Series, n. 1)

LAVE, J.; WENGER, E. Situated learning: legitimate peripheral participation. Cambridge: Cambridge University Press, 1991.

McNIFF, J. Action research for professional development. Dorset: September Books, 2010.

MOSS, P.; DAHLBERG, G.; GRIESHABER, S. The organisation for economic co-operation and development's international early learning study: opening for debate and contestation. Contemporary Issues in Early Childhood, v. 17, n. 3, p. 343-351, 2016.

MOSS, P.; URBAN, M. The organisation for economic co-operation and development's international early learning study: what happened next. Contemporary Issues in Early Childhood, v. 18, n. 2, p. 250-258, 2017. 
MUNTON, A. G.; MOONEY, A.; ROWLAND, A. Deconstructing quality: a conceptual framework for the new paradigm in day care provision for the under eights. Early Childhood Development and Care, v. 114, p. 11-18, 1995.

NEAUM, S. School readiness and pedagogies of competence and performance: theorising the troubled relationship between early years and early years policy. International Journal of Early Years Education, v. 24, n. 3, p. 239-253, 2016.

PASCAL, C. Capturing the quality of education provision for young children: a story of developing professionals and developing methodology. European Early Childhood Education Research Journal, v. 1, n. 1, p. 69-80, 1993.

. Humanising early childhood education. In: ROYAL SOCIETY OF ARTS CONFERENCE, 1997, London.

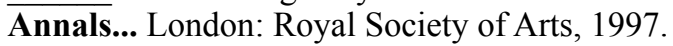

Effective early learning: an act of practical theory. European Early Childhood Education Research Journal, v. 11, n. 2, p. 7-28, 2003.

PASCAL, C.; BERTRAM, T. Desenvolvendo a qualidade em parcerias: nove estudos de caso. Porto: Porto Editora, 1999. (Coleção Infância, nº 6).

Effective early learning: evaluating and developing quality in early childhood settings. Worcester: Amber Publications, 1996.

Accounting Early for Life Long Learning (AcE) Programme. Worcester: Amber Publications, 2008.

Listening to young citizens: the struggle to make real a participatory paradigm in research with young children. European Early Childhood Education Research Journal, v. 17, n. 2, p. 249-262, 2009.

Praxis, ethics and power: developing praxeology as a participatory paradigm for early childhood research. European Early Childhood Education Research Journal, v. 20, n. 4, p. 477-492, 2012.

PASCAL, C.; BERTRAM, T.; COLE-ALBÄCK, A. What research tells us about effective pedagogic practice and children's outcomes in the reception year. The Hundred Review Report. Huddersfield: Early Excellence, 2017. p. 1-35.

PASCAL, C.; BERTRAM, T.; MOULD, C. Exploring the relationship between process and outcome in young children's learning: stage one of a longitudinal study. International Journal of Educational Research, v. 29, n. 1, p. 51-67, 1998.

REASON, P.; BRADBURY, H. (Ed.). Sage handbook of action research: participative inquiry and practice. 2. ed. London: Sage Publications, 2008.

ROSSBACH, H. G.; CLIFFORD, R. M.; HARMS, T. Dimensions of learning environments: cross national validation of the ECERS. In: AERA Annual Conference, 1991, Chicago. Annals... Chicago: AERA, 1991.

VYGOTSKY, L. S. Mind in society: the development of higher psychological processes. Cambridge: Harvard University Press, 1978.

Recebido em: 18/03/2018

Aprovado em: 01/04/2018 